\title{
Study on the effect of EGR control parameters on turbocharged diesel engine
}

\author{
Le Liu ${ }^{1, *}$, Lihui Wang ${ }^{1}$, Peilin Geng ${ }^{1}$, Xionghui Zou ${ }^{1}$, and Kaibo $\mathrm{Yu}^{2}$ \\ ${ }^{1}$ China Automotive Technology \& Research Center, Tianjin 300300, China \\ 2 Jilin University, State Key Laboratory of Automotive Simulation and Control, Changchun, China
} Keywords: turbocharged diesel engine, transient condition, EGR,
exhaust oxygen concentration.

\begin{abstract}
Under transient conditions, the emission of turbocharged diesel engine will deteriorate to a certain extent, and the adoption of EGR is also a factor leading to the increase of some pollutants. For this reason, a high pressure common rail turbocharged and inter-cooled heavy duty diesel engine was used to study the influence of EGR closed-loop control method on the emission performance under typical transient conditions with constant speed and torque increasing in 5s. The results show: The NOx emission can not be effectively reduced when the air input is used as feedback parameter; When the intake oxygen concentration is used as feedback parameter, smoke emission will increase sharply; When exhaust oxygen concentration is used as feedback parameter, the smoke deterioration is less, the peak smoke is $15.8 \%$. It has a better compromise relationship with NOx and fuel consumption, and can be used as closed-loop control parameter for diesel engine transient performance optimization.
\end{abstract}

Vehicles are mostly running in transient condition, especially for heavy commercial vehicle with turbocharged diesel engine. Intake lag after fuel injection is very serious under transient condition, which leads to deterioration of diesel engine performance ${ }^{[1-2]}$. Compared with steady-state conditions, there are some problems in transient conditions, such as noise surge, emission and fuel economy deterioration $\left[^{3-5]}\right.$. This feature becomes more prominent after the introduction of EGR system, which is one of the current research focuses in the field of transient conditions of internal combustion engines. In the control of EGR valve in transient process, previous studies show that it is inevitable that EGR overshoot and performance deterioration will occur when steady-state optimization EGR valve opening characteristics are directly applied to the control of EGR valve in transient process $^{[6]}$. An Xiaohui et al. ${ }^{[7]}$ studied the feedback control parameters of EGR system based on GT-Power software, and found that progress has been made. Oxygen concentration is only related to EGR rate and AFR rate, and is linear with EGR rate, which indicates that oxygen mass fraction is more suitable as a feedback control parameter under transient conditions than EGR rate. But in practical application, the responsiveness of

\footnotetext{
${ }^{*}$ Corresponding author: liule@ catarc.ac.cn
} 
oxygen sensor and EGR valve is very stringent; Zhang Zhengxing ${ }^{[8]}$ and others carry out PI (proportional integral) closed-loop control of EGR opening according to the deviation between the target value and the actual value of engine intake; on this basis, Chen Haoping [9] and others found the adaptability of traditional PID control mode. The control accuracy and responsiveness of EGR are improved by adding a feed forward module.

In order to obtain the smoke and NOx compromise emissions in the transient process as the main objective, the author intends to use the closed-loop control strategy of EGR valve opening to explore the influence of typical constant speed and increased torque transient process performance on a high-pressure common rail, turbocharged and inter-cooled heavy-duty diesel engine, and provide research ideas and data support for the development of the transient performance of heavy-duty diesel engine.

\section{Test bench and control system}

\subsection{Test bench}

The research object is a high-pressure common rail electronic-controlled diesel engine with two-stage turbocharging system. Its main technical parameters are shown in Table 1 . The layout of diesel engine test bench and measurement and control system is shown in Figure 1. High-pressure EGR loop circulation mode is selected. The exhaust gas is extracted before the high-pressure stage turbine, and then it passes through the EGR inter-cooler (exhaust gas cooling) and EGR valve (control exhaust gas flow) in turn. Finally, it is introduced into the high-pressure stage compressor.

Table 1. Main parameters of diesel engine for test.

\begin{tabular}{ll}
\hline Technical parameter & Value \\
\hline Type & Water-cooled in-line 6 cylinders \\
Diameter $/ \mathrm{mm} \times$ Piston stroke/mm & $112 \times 145$ \\
Total displacement $/ \mathrm{L}$ & 8.6 \\
Compression ratio & 17 \\
Rated power $/ \mathrm{kW}$ & $257\left(2100 / \mathrm{r} \cdot \mathrm{min}^{-1}\right)$ \\
Maximum torque $/(\mathrm{N} \cdot \mathrm{m})$ & $1500\left(1300 \mathrm{r} \cdot \mathrm{min}^{-1}\right)$ \\
Injection System & Bosch High Pressure Common Rail \\
Intake type & Turbocharged Inter-cooled \\
Turbocharger & HOLSET400 \\
\hline
\end{tabular}

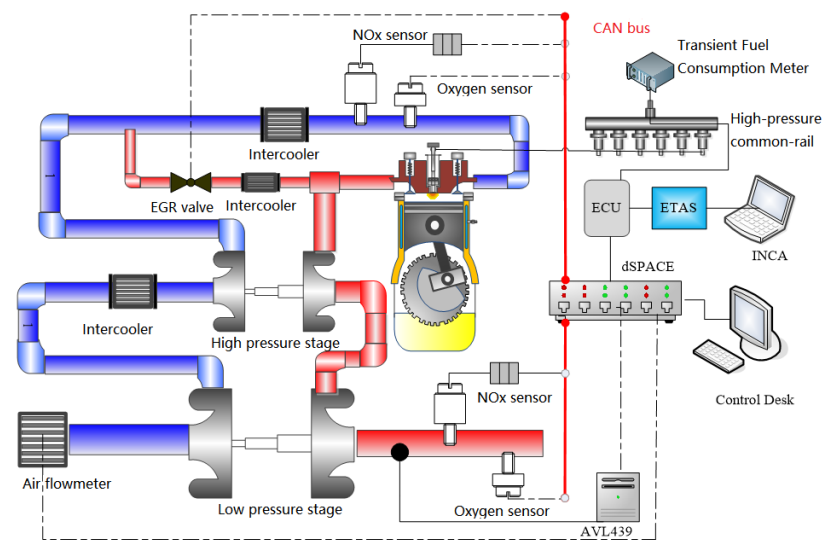

Fig. 1. Diagram of transient test bench and measurement and control platform. 
In this study, a real-time parameter acquisition system $(10 \mathrm{~ms})$ is constructed with high-speed sensors and millisecond A/D acquisition card, which can realize the real-time acquisition of diesel engine parameters such as speed, torque, intake and exhaust temperature and pressure, extinction smoke, intake flow rate and exhaust emissions. Under common rail platform, the final signal of engine working condition control is throttle voltage. With the advantages of high response and high precision of single chip computer, and combined with eddy current dynamometer, typical transient working conditions can be reproduced.

EGR rate is accurately and rapidly measured by EGR5230 control system. Similar to the traditional $\mathrm{CO} 2$ tracer method, EGR5230 uses oxygen concentration of intake and exhaust to calculate EGR rate. At the same time, the instrument has its own calibration function to ensure the responsiveness of EGR measurement. The calculation formula of EGR rate in this experiment is as follows:

$$
E G R \%=\frac{\left(\mathrm{O}_{2}\right)_{a t m}-\left(\mathrm{O}_{2}\right)_{\text {int }}}{\left(\mathrm{O}_{2}\right)_{\text {atm }}-\left(\mathrm{O}_{2}\right)_{\text {exh }}} * 100 \%
$$

In the above formula: (O2)int is intake oxygen concentration, (O2)exh is exhaust oxygen concentration, (O2)atm is air ambient oxygen concentration.

\subsection{Control system}

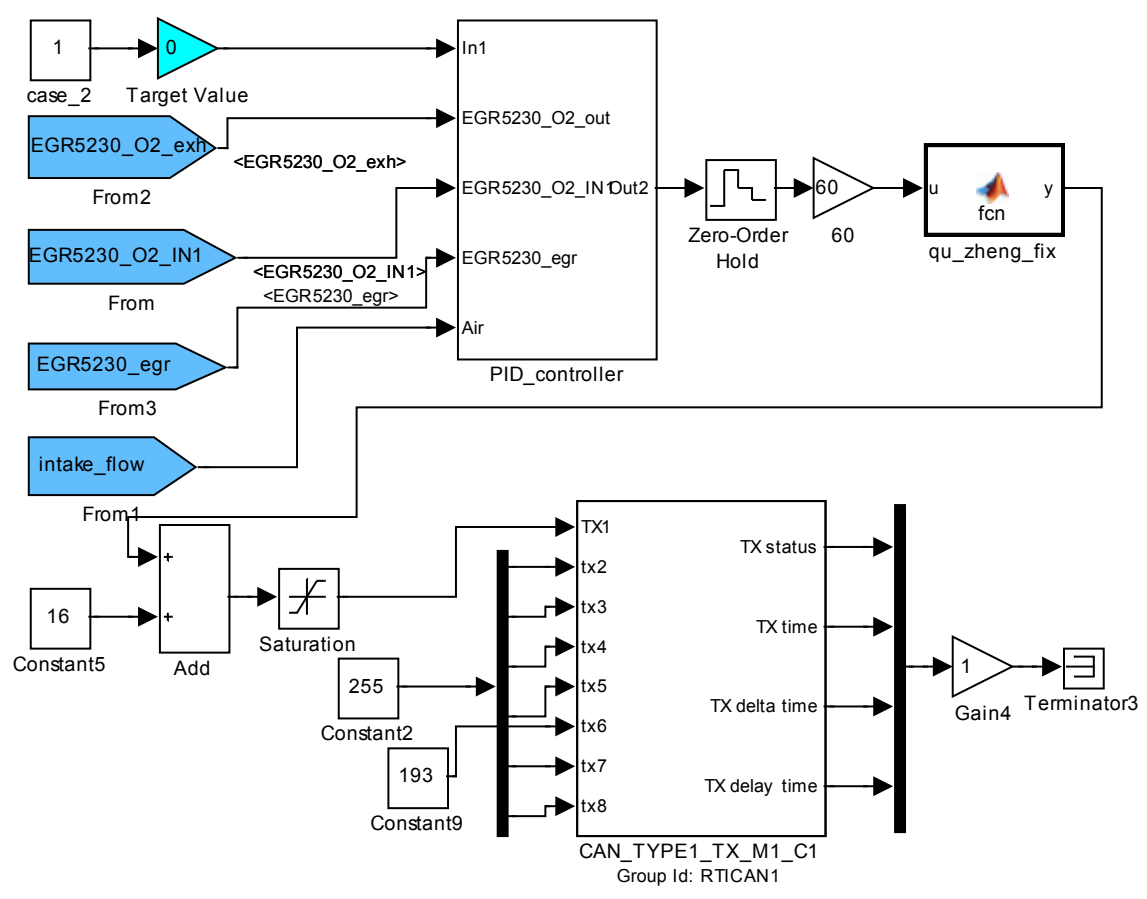

Fig. 2. EGR Valve Sending Data Control. 


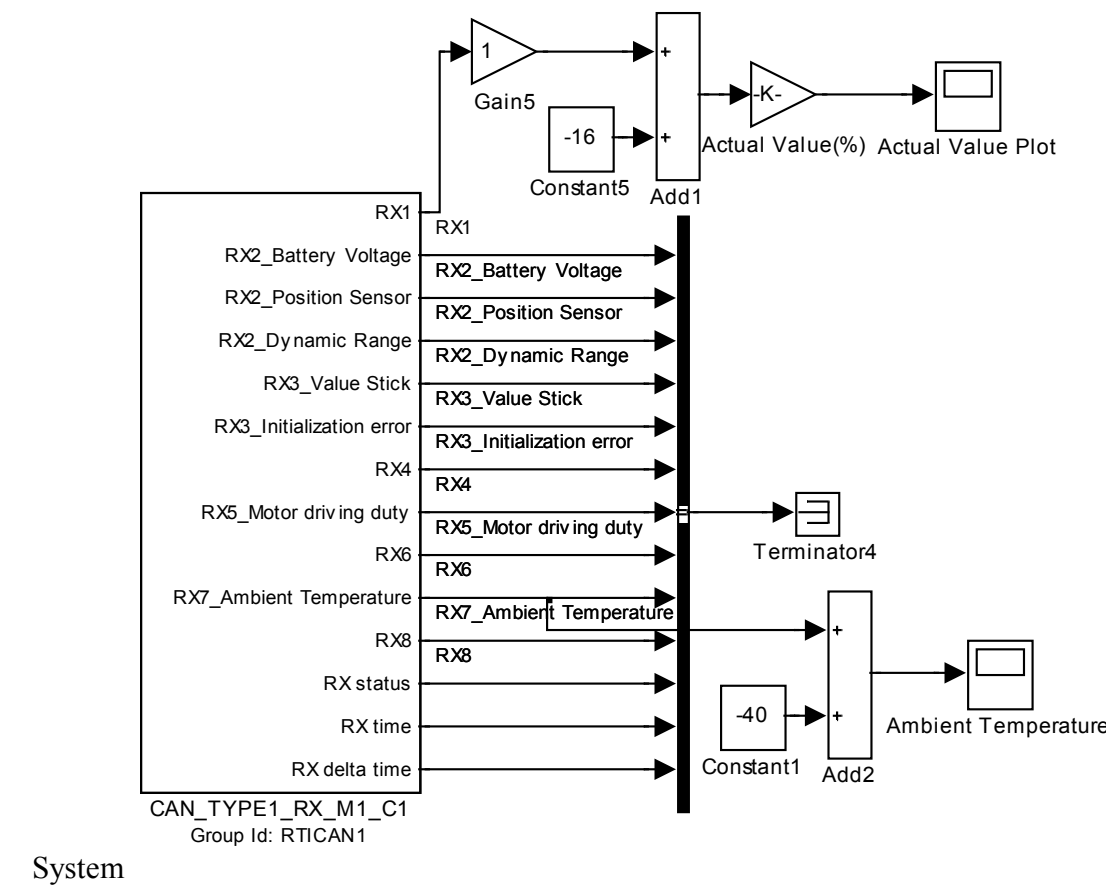

Fig. 3. EGR Valve Acceptance Data Control System.

Typical transient conditions (constant speed $1650 \mathrm{r} / \mathrm{min}$ (B speed) and constant speed and increasing torque from $10 \%$ to $100 \%$ linearly in 5 seconds are tested. The throttle opening is realized by using the DAC module of dSPACE to output voltage signal in real time and convert it into the corresponding cyclic fuel injection quantity in ECU. Based on CAN bus and with opening feedback, the electronic control EGR valve is controlled by closed-loop PID mode of dSPACE platform. The sending and receiving messages of EGR valve are shown in figs. 2 and 3 respectively. Aiming at the typical constant speed and increasing torque transient process, the effects of closed-loop control of EGR valve on the transient performance of diesel engine were studied by taking the air volume, oxygen concentration in intake and oxygen concentration in exhaust as feedback variables. The corresponding test plan will be explained in each section.

\section{Test results}

The closed-loop control is realized by PID (Proportion Proportion Ratio, Integration Integration, Differentiation Differentiation) controller, and the single factor that distinguishes different control strategies is the feedback scalar. Considering the non-linear, time-delay and complex ventilation characteristics of the EGR system, when selecting feedback variables, it is required that variables not only reflect the current state of the engine EGR system, but also have the characteristics of fast response, accurate response, reliable operation and convenient measurement. So the intake volume, intake oxygen concentration and exhaust oxygen concentration, which can be quickly and accurately measured, are selected as feedback variables in the experiment. The characteristics of the above parameters during the original transient loading process (without EGR) are taken as control objectives (low peak smoke during the original transient process, and no significant deterioration of fuel economy compared with the corresponding steady-state conditions ). 


\subsection{Transient performance based on air input}

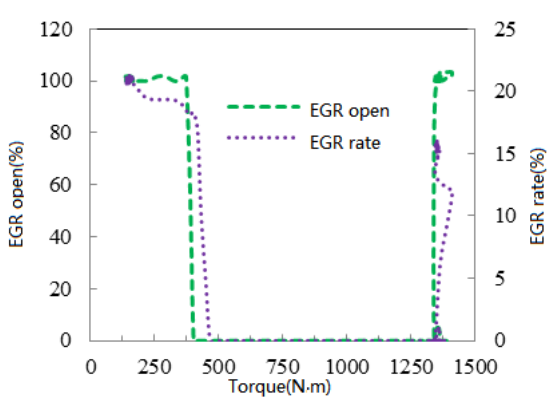

(a)

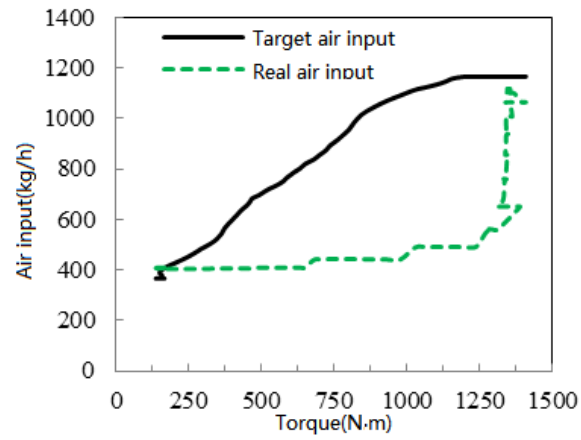

(b)

Fig. 4. Experimental scheme based on air input.

Since the intake value is easy to obtain, the intake value is selected as the closed-loop feedback variable in order to explore the influence of transient performance. During the test, it was found that, no matter how the parameters of the PID controller (Kp, Ki and $\mathrm{Kd}$ ) were adjusted, the EGR valve closed immediately after the start of the transient process and opened suddenly after the end of the transient process (Fig. 4a). The reason for this phenomenon is that there is a big difference between the actual intake and the target intake in the transient process (Fig. 4b), and the intake lag is serious. The intake gradually restores the steady state value after the transient process.

Fig. 5-6 presents the emission characteristics of diesel engine under closed-loop feedback control based on intake volume, and compares with the transient process performance of original engine without EGR. Because the EGR valve is almost fully opened in the early stage of the transient process (see Fig. 4a), the poor oil-gas mixing results in delayed combustion phase, lower combustion rate and peak extinction smoke emission, but the NOx emission is effectively limited (the initial time of the transient process is reduced by $31.5 \%$ ). In addition, the effective fuel consumption rate is little different from the original engine value, and slightly reduced in the small load area.

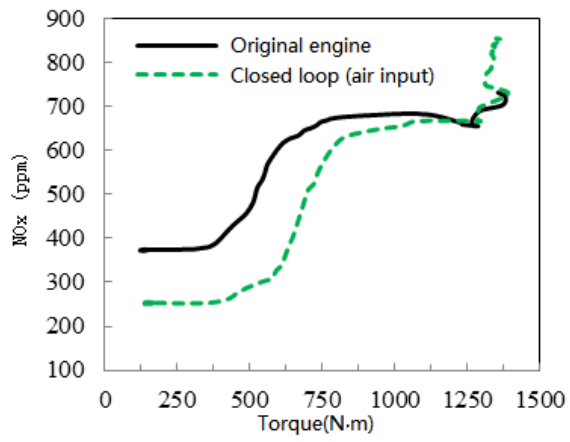

(a)

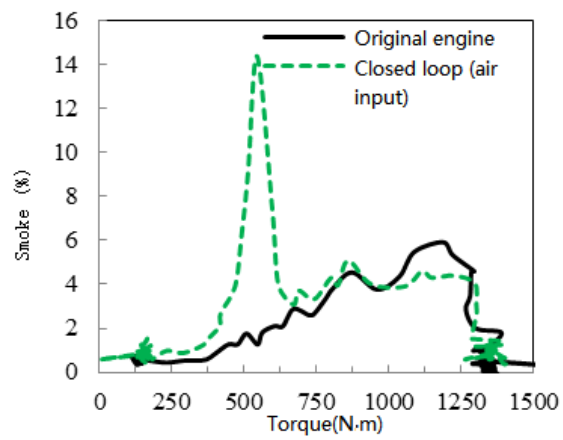

(b) 


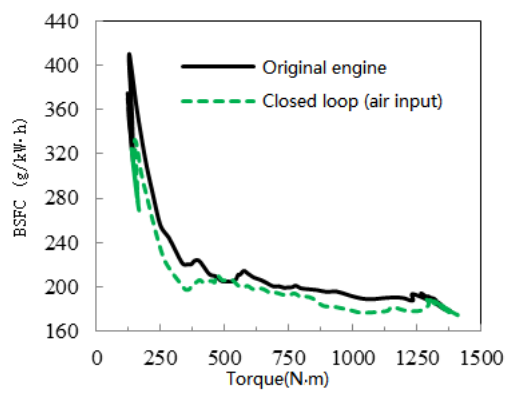

(c)

Fig. 5. Diesel engine performance and emissions based on air input.

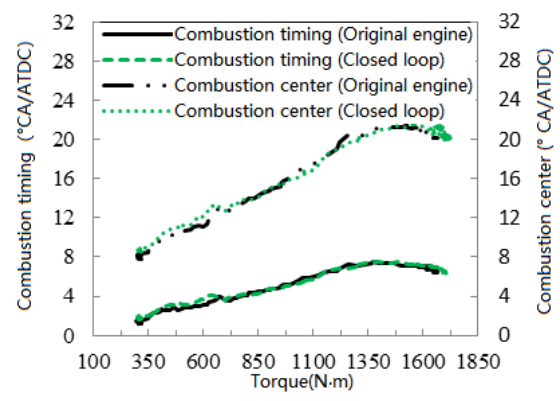

Fig. 6. Combustion performance of diesel engine based on air input.

\subsection{Transient performance based on feedback of intake oxygen concentration}

In order to study the transient performance based on oxygen concentration feedback, the parameters of the PID controller $(\mathrm{Kp}=3.5, \mathrm{Ki}=0.008, \mathrm{Kd}=0.001)$ were first tuned through experiments. The experimental results are shown in Figure 7. Compared with Figure $7 \mathrm{a}$ and Figure $4 \mathrm{a}$, it can be seen that the action trend of EGR valve is the same. The difference is that the closing time of EGR valve is shorter based on oxygen concentration feedback, which is mainly related to the parameter setting of PID controller. In order to avoid the frequent opening or closing of EGR valve in the transient process (the test shows that the opening or closing action of EGR valve will cause obvious fluctuation of exhaust gas flow and bring adverse effects on transient performance), the sensitivity of the controller to variable changes should not be too large. Figure $7 \mathrm{~b}$ shows the following relationship between the actual intake oxygen concentration and the target intake oxygen concentration (the difference of oxygen concentration is less than $2.2 \%$ ).

Fig. 8-9 shows the transient process performance and combustion characteristic parameters of diesel engine under closed-loop feedback control based on oxygen concentration in intake air. The transient process performance of diesel engine without EGR is compared with that of original engine. Because the opening of EGR valve is always greater than $75 \%$ before the heavy load, the insufficient intake in the transient process is aggravated, and the combustion deterioration is serious (the high EGR rate causes the delay of combustion phase in the transient process).

In view of the continuous high EGR rate during the transient process, the smoke emission is extremely high, while the NOx emission before the closure of the EGR valve is low (peak value is less than $300 \mathrm{ppm}$ ), but with the closure and reopening of the EGR valve, the second peak value of NOx emission appears (peak value is $511 \mathrm{ppm}$ ). The difference of intake and exhaust pressure is greater than the original level before the EGR valve closes, 
but with the EGR valve closing, the fluctuation of exhaust gas flow causes the difference of intake and exhaust pressure to decrease (lower than the original level). In contrast, when the combustion deterioration loss plays a secondary role, the effective fuel consumption rate under closed-loop control is lower than that of the original engine (below $600 \mathrm{~N} \cdot \mathrm{m}$ ), but higher than that of the original engine (above $600 \mathrm{~N} \cdot \mathrm{m}$ ).

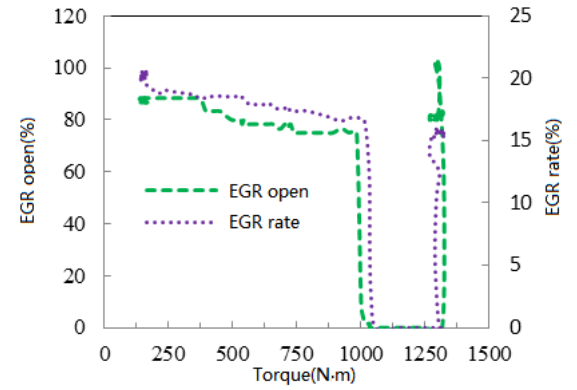

(a)

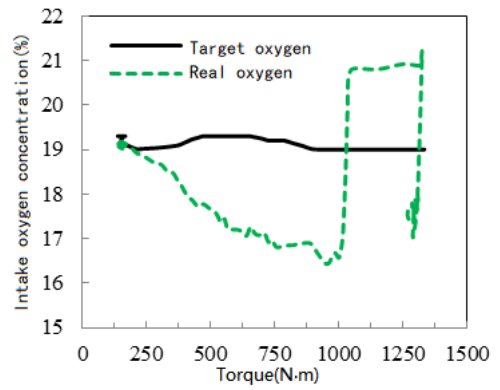

(b)

Fig. 7. Experimental scheme based on intake oxygen concentration feedback.

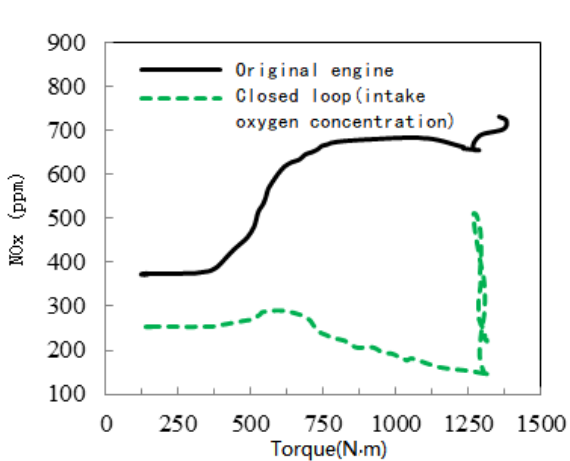

(a)

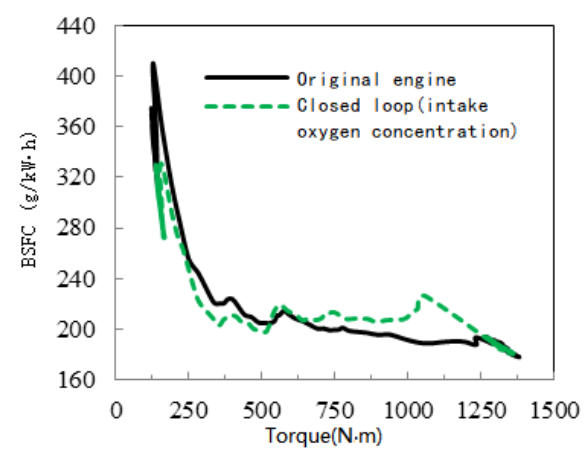

(c)

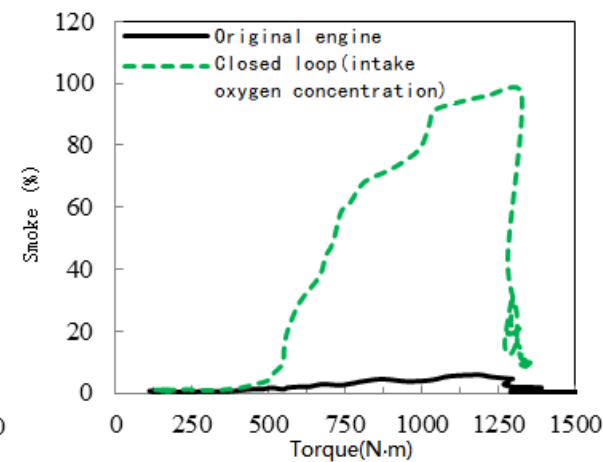

(b)

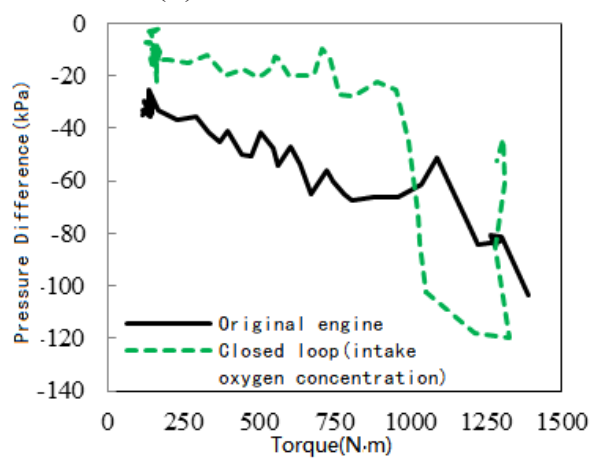

(d)

Fig. 8. Diesel engine performance based on intake oxygen concentration feedback. 


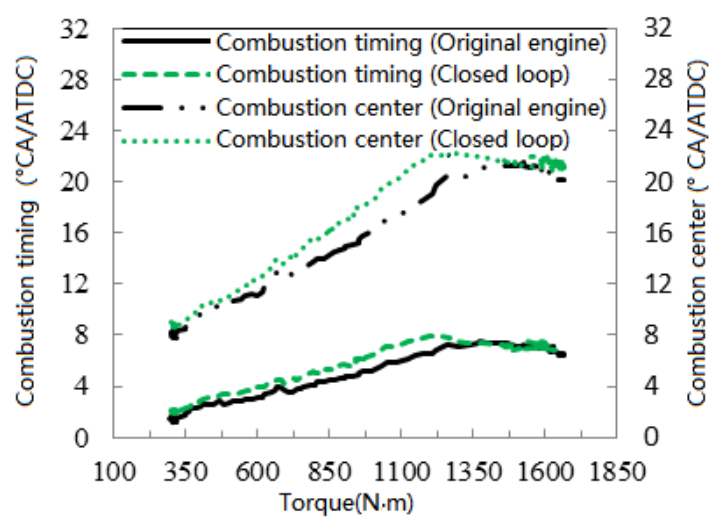

Fig. 9. Combustion performance of diesel engine based on intake oxygen concentration feedback.

\subsection{Transient performance based on feedback of exhaust oxygen concentration}

Among the two control variables of EGR rate and oxygen concentration, the oxygen concentration index is more suitable as the feedback variable of transient control. The oxygen concentration value of the original machine in the transient process is measured directly by the ample oxygen sensor. In this study, the exhaust oxygen concentration is used as feedback variable, and the optimal value of exhaust oxygen concentration of the original engine in the transient process is used as the reference of the control MAP. Firstly, the three parameters required by the PID controller $(\mathrm{Kp}=1.5, \mathrm{Ki}=0.005, \mathrm{Kd}=0.002)$ are determined preliminarily through the parameter tuning test. The experimental results are shown in Figure 10. The change trend of EGR rate in transient process is high at both ends and low in the middle (corresponding to the change of EGR valve opening, see Fig. 10a). The actual exhaust oxygen concentration has a good follow-up with the target exhaust oxygen concentration (the difference is less than $2 \%$, see Fig. 10b).

Fig. 11-12 shows the transient process performance and combustion characteristic parameters of diesel engine under closed-loop feedback control based on exhaust oxygen concentration. The transient process performance of diesel engine is compared with that of original engine without EGR. Under the feedback control, the maximum opening of EGR valve is only $12 \%$, and it keeps a small opening during the transient process. The combustion condition in cylinder is still good, and the emission of NOx and smoke show a good compromise. The peak value of NOx emission $(548 \mathrm{ppm})$ in the transient process is $21.7 \%$ lower than that of the original engine, and the peak value of extinction smoke is $15.8 \%$. Effective fuel consumption rate is not much different from that of the original engine, especially under the condition of small load, because the opening of EGR valve reduces the loss of pump gas, the fuel consumption rate decreases slightly. 


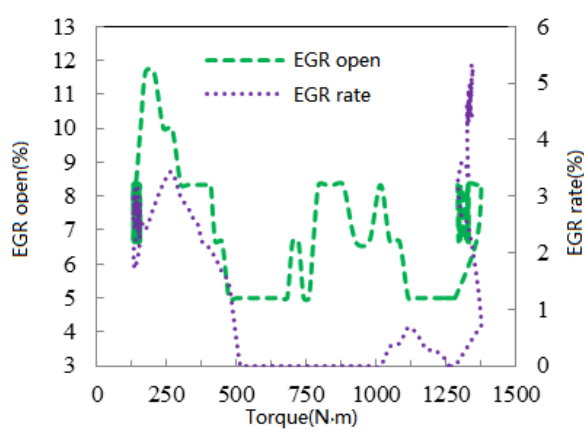

(a)

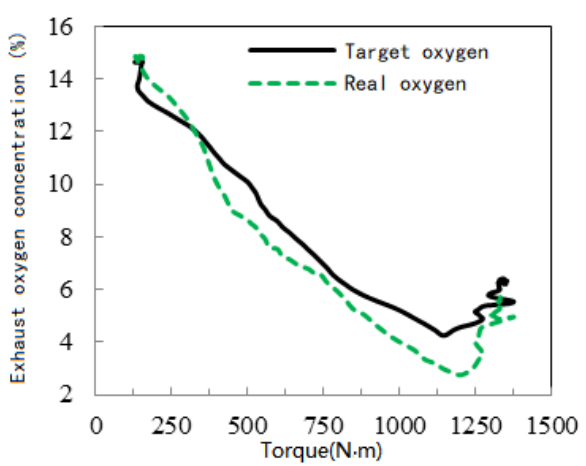

(b)

Fig. 10. Experimental scheme based on feedback of exhaust oxygen concentration.

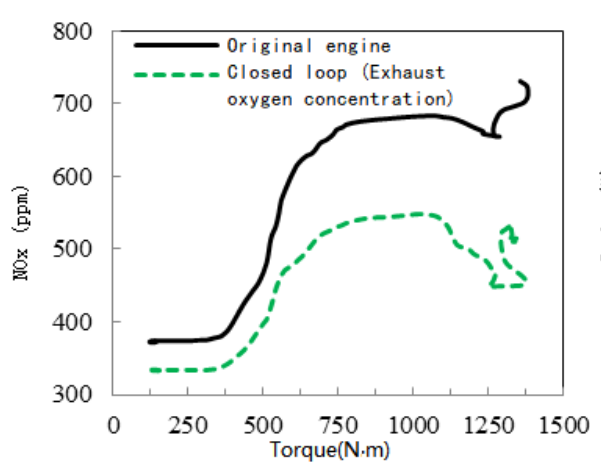

(a)

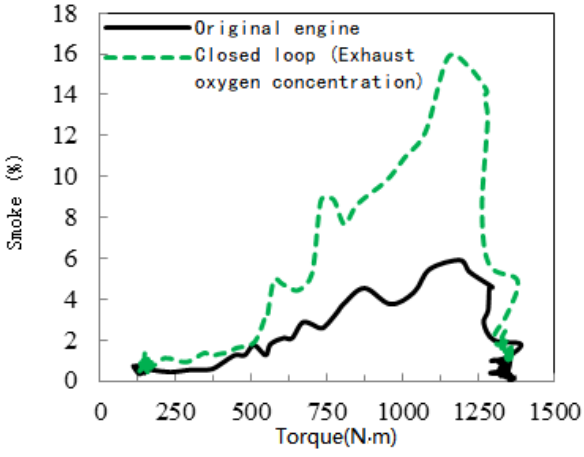

(b)

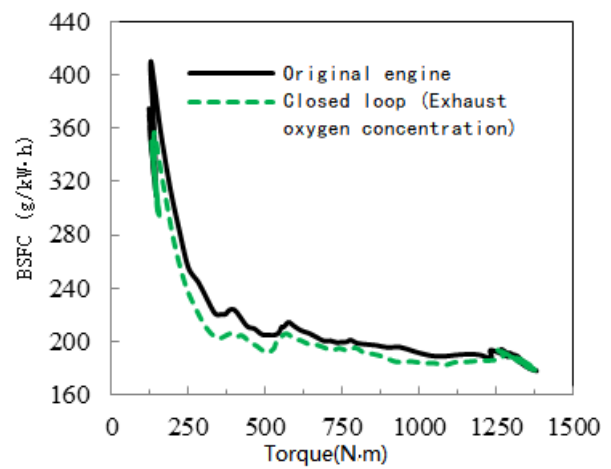

(c)

Fig. 11. Performance and emissions of diesel engines based on exhaust oxygen concentration feedback. 


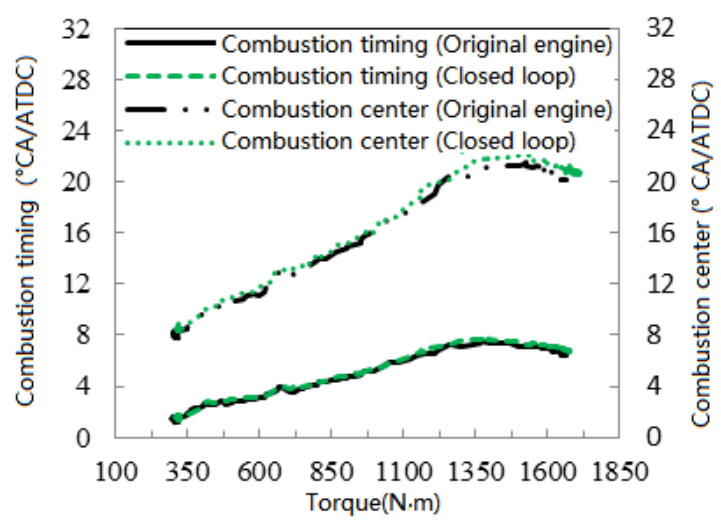

Fig. 12. Combustion performance of diesel engine based on exhaust oxygen concentration feedback.

\section{Conclusion}

In order to adapt to the increasingly stringent emission regulations of diesel engine, the introduction of EGR system in the process of diesel engine transient loading has appeared more serious deterioration characteristics, so the closed-loop control method of EGR valve is particularly important. The selected feedback variable should not only reflect the current state of the engine system, but also have the characteristics of fast response, accurate response, reliable operation and convenient measurement. Combining with the modified transient control MAP (referring to the original exhaust oxygen concentration value in the transient process of the original engine), and comparing the three feedback control variables of intake volume, intake oxygen concentration and exhaust oxygen concentration, the exhaust oxygen concentration may cause the extinction smoke to deteriorate to a certain extent, and the EGR overshoot characteristic still exists, but it can be better. There is a trade-off between smoke, NOx and fuel consumption.

\section{Reference}

1. Zhang Longping, Liu Zhongchang, Tian Jing, et al. Dynamic Response and Combustion Deterioration Analysis of a Diesel Engine Under Transient Operations. Transactions of CSICE, 2014,32(2) :104 110.

2. Nilsson T,Froberg A,Aslund J, et al. Optimal operation of a turbocharged diesel engine during transients[C]. SAE Paper 2012-01-0711 . 2012.

3. M.J. Samulski, C.C. Jackson. Effects of Steady-State and Transient Operation on Exhaust Emissions from Nonroad and Highway Diesel Engines[C]. SAE 982044, 1998

4. William Glewen, David Heuwetter, David Foster, et al. Analysis of Deviations from Steady State Performance During Transient Operation of a Light Duty Diesel Engine[C]. SAE Paper, 2012-01-1067.

5. Hagena J R, Filipi Z S, Assanis D N. Transient diesel emissions: Analysis of engine operation during a tip-in[C]. SAE Paper, 2006-01-1151.

6. Tian Jing, Zhao Yunlong, et al. Study on EGR optimization strategy for transient process[J]. Transactions of CSICE, 2011, (06):489-494. 
7. An Xiaohui, Liu Lanbo, et al. Simulation of the Effect of Intake Charge Oxygen Concentration Based EGR on Diesel Engine Performance. Transactions of CSICE, 2013, 31(2) : 115-119.

8. Zhang Zhengxing, et al. Research on Closed-loop Control Strategy of Diesel EGR System Based on PID[J]. Automobile Technology, 2014, (05): 54-57.

9. Chen Haoping, et al. Control Strategy for Electronic Control EGR of High-pressure Common Rail Diesel Engine Based on ASCET Platform[J]. Vehicle Engine, 2010, (06): 26-29. 